\title{
The Design of Folio Shielding Door
}

\author{
Lan $\mathrm{Mi}^{1}$ \\ ${ }^{1}$ Environmental Management College of China, No. 8 Golden Harbor Road,Beidaihe District, Qinhuangdao City, Hebei province, China
}

\begin{abstract}
Through analyzing a case of the design of a folio shielding door, the design and key technology of the equipment are shown.

KEYWORD: a folio shielding door; the design
\end{abstract}

An auto-opening electromagnetism-shield waveabsorbing door is needed by a dark room program, whose net opening size is $4 \mathrm{~m} \times 5 \mathrm{~m}(\mathrm{~W} \times \mathrm{H})$, and $700 \mathrm{~mm}$ waveabsorbing material is needed to be pasted on the door leaf.

\section{The Confirmation of the Designing Project}

At the beginning, it was considered to put in use the mature pneumatic flat-pressing electric translating waveabsorbing door, which had been examined reliable by various projects. Due to the fact that the net width of shield containing room was $8.5 \mathrm{~m}$ and winding lines were needed by the sides of the room, the door did not enjoy enough space. The second option was vertical-lift waveabsorbing door. After calculating, it was figured that the net height of the containing room was merely $9.5 \mathrm{~m}$, that of the doorway was $5 \mathrm{~m}$, the minimum height of the lift door was $10 \mathrm{~m}$, and installing the leaf door frame needed some space as well. Therefore, the space was not enough for the vertical-lift wave-absorbing door too. Eventually, the door was expected to be a auto-rotating folio one. While the further calculation found when the door was $90^{\circ}$-opened, the actual net open size of the door was $2.6 \mathrm{~m}$, but the maximum width of transporting car was $3.2 \mathrm{~m}$. When the door was $145^{\circ}$-opened, the figure was $3.6 \mathrm{~m}$. It was sufficient for the equipment and car to enter, getting into the shield room. However, new problem occurred, which was the interference of door leaf and winding lines. After negotiating with the general engineer and process designers, the positions of the wind lines were adjusted, and the require was met.It was calculated when either the high end or the low end of the door leaf was pressed, the volume of deformation was approximately $10 \mathrm{~mm}$. When the door switch was put in the middle of the door leaf, none of the structure considered were able to meet the

\footnotetext{
a Corresponding author: author@e-mail.org
}

demand of power for switching the door. Single-spot pressing would increase the deformation of the door leaf, which would influence the function shielding. A pressing equipment was needed to meet the standard.

\section{The Specifications and Parameters of the Door}

Specification: $4 \mathrm{~m} \times 5 \mathrm{~m}(\mathrm{~W} \times \mathrm{H})$

Time for Opening : about $110 \mathrm{~s} \times 2$

Time for shutting : about $110 \mathrm{~s}+125 \mathrm{~s}$

Way of Switching: auto-control

Opened Door Leaf : $145^{\circ}$

Screen Index: $100 \mathrm{MHz} \sim 10 \mathrm{GHz} \geq 100 \mathrm{~dB}$

$10 \mathrm{GHz} \sim 18 \mathrm{GHz} \geq 90 \mathrm{~dB}$

\section{Operating Principle and Structure}

The size of the entrance is $4 \mathrm{~m}$ (width) $\times 5 \mathrm{~m}$ (height). As shown in the figure 1, the operating time of each door leaf is $110 \mathrm{~s}$. The door is made up of door frame(1-0),door leaf (2-0), door leaf(3-0),hinge(4-0), chain wheel, lower part pressing system, chain installing frame, installing gantry, reduction box, trundle and chains. Chain wheel, driven by reduction box, rotates on the chains, motivating the door to open and close. As shown in the figure 2, lower part pressing structure is hidden beneath the ground at the entrance when it does not work. When the door is closed, it presses the lower part of the door tightly, making sure the door is closed well. Thus the electric continuity between door leaves and that of door leaf and door frame is ensured, and the shielding function of the door thus improved. A standard small shielding door is installed on the door leaf(2-0) for operators to go through. There is a trundle installed on the low part of the door 
leaf to reduce the burden of hinge on it, enlightening door leaf's deformation.
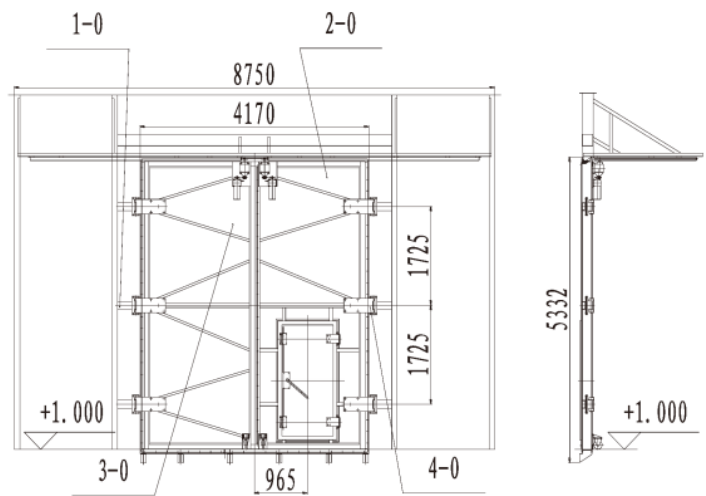

Figure 1. diagrammatic drawing of the door

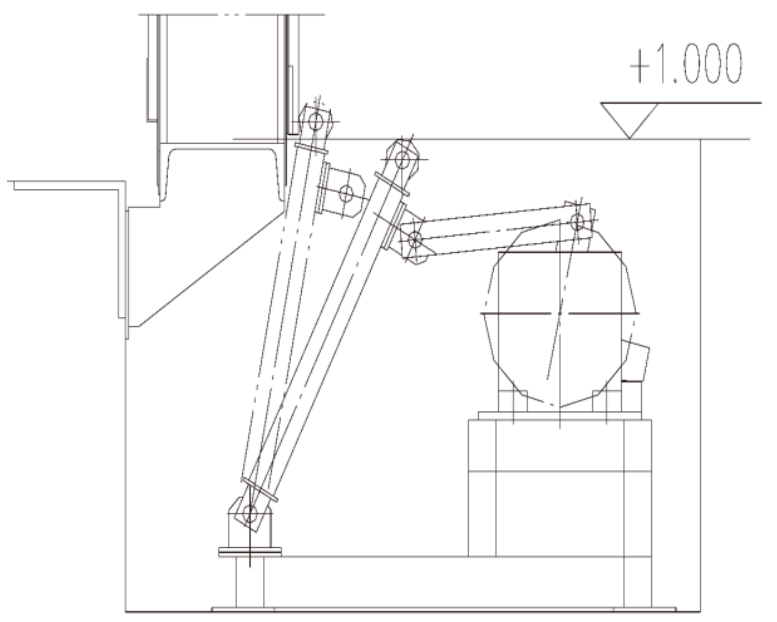

Figure 2. Lower compression mechanism

While designing the door leaf, it is examined that most power is needed when the door is opened at the first stage. Therefore, cants are arranged to put face-to-face for the gaps between door leaf and door frame and door leaves.In this way, the finer-shaped spring piece will provide a divided power vertical to the door, reducing the power needed when the door is opened. The door leaves are welded, so it is hard to remain the gaps between the leaves and frame balanced and unchanged. A adjusting board is added to make it possible to adjust the gaps on the spot, making the shielding function achievable. As shown in the Figure 3, Bronze boards are pasted on the leaves and frame, two finger-shaped beryllium -bronze springs and a electric foam are fixed on the bronze board which is on the door leaves. When the door is closed, the finger-shaped spring will shrink because of inertia, ensuring good electric continuity between door frame and leaves and improving the shielding ability of the door. The structure is shown in the figure 4. The gap is made with a certain angle between the door frame and leaves to reduce the resistance while opening it.

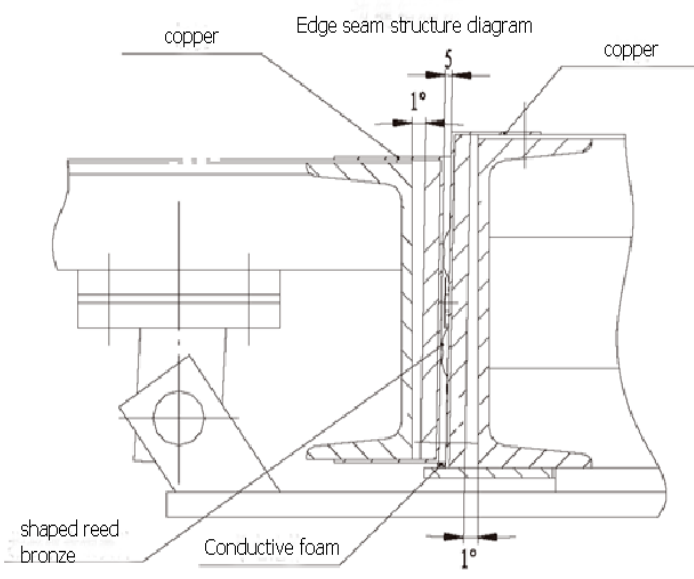

Figure 3. edge seam structure

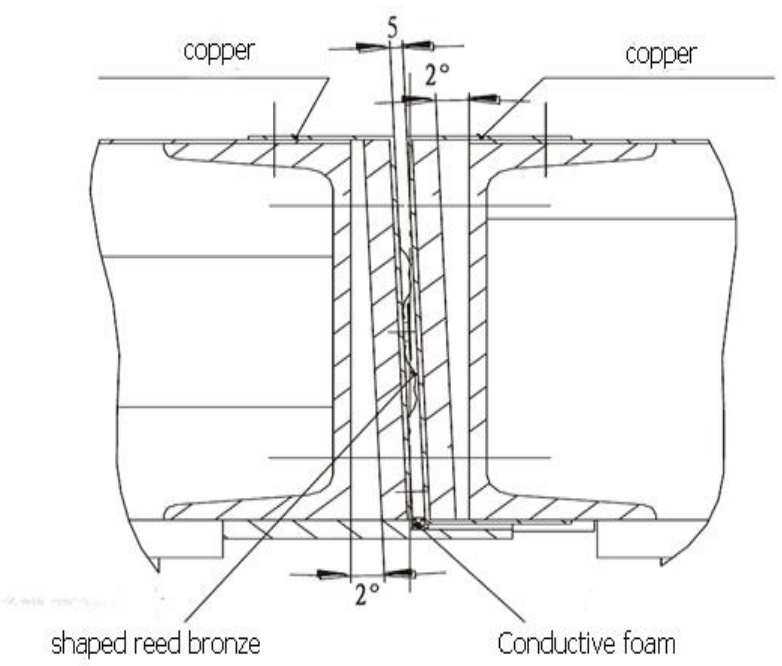

Figure 4. Structure of raphe

\section{Conclusion}

For shielding project, higher screen standard is easily realized in single-leaf door, and various mature products have been made. However, for, folio-shield door, a T-shape gap will from between the door leaves and frame, the shielding ability will reduce after times of switching. About $80 \mathrm{~dB}$ of shielding doors have the effort above $10 \mathrm{GHZ}$ after being operated by general measures. This project is a successful exploration of folio-shield door for it is able to reach $103 \mathrm{~dB}$ based on 10GHZ's effort and meet other ranges of dark room demand.

\section{References}

1. R.O.Duad,P.E.Hart. Use of Hough Transformation to Detect Lines and Curves in Pictures.Communica tions of the ACM,14,9(1972)

2. I.Mikic,P.Cosman,G.Kogut,andM.M.Trivedi.Movi ng shadow and object detection in traffic scenes.[J]Proceedings of International Conf erence on Pattern Recognition,(2000)

3. Johnson J P.Ehsani M.Guzelgunler Y Review of se nsorless methods for brushlessDG.Industry Applic ations Conference,38(1999) 
4. Yoshida M.Murai YTakada M Noise reduction by $\mathrm{t}$ orque ripp lesupperssion in brushless DC motor (1 998) 